\section{Access to journals through peer reviewers}

In a CMAJ editorial, John Fletcher states that the bread and butter of an academic journal is disseminating science, ${ }^{1}$ which is also an ethical imperative of researchers and academics who contribute to the processes of peer review for scientific publications. Some journals give their peer reviewers free access to their journals as a token of thanks, but how frequently is this policy practised? ${ }^{2}$ And what about reviewers who already have institutional access to many journals? Perhaps they could donate their complimentary journal subscriptions to others who might find subscriptions more useful (i.e., those in low- or middleincome countries).

We surveyed several editors of highimpact subscription-based journals (14 general medical and 7 nursing or disability) to determine whether they provided reviewers with complimentary journal access and, if so, whether reviewers were allowed to donate these subscriptions to others (See Appendix, available at www.cmaj.ca/lookup/suppl /doi:10.1503/cmaj.112-2056/-/DC1). Of the 21 journals, 20 were members of the Health InterNetwork Access to Research Initiative (HINARI), the World Health Organization's program that provides free or low-cost online journal access in the developing world. ${ }^{3}$ However, only three journals gifted reviewers with free journal access (BMJ and Journal of Intellectual \& Developmental Disability for 12 months and The Lancet for 3). Only BMJ and The Lancet allowed reviewers to donate these subscriptions to others.

Health care workers in low-income countries may not have institutional affiliations, and people from middle- or high-income countries (e.g., Singapore) may not qualify for HINARI, but frequently cannot afford journal subscriptions. ${ }^{4}$ We believe that more journals should provide peer reviewers with free subscriptions that could be donated to others.
Richard G. McGee MMed, Bronwyn Hemsley PhD, Peter J. Gill BMSc Sydney School of Public Health, University of Sydney; and the Centre for Kidney Research, the Children's Hospital at Westmead (McGee); School of Humanities and Social Sciences, University of Newcastle, New South Wales, Australia (Hemsley); and the Department of Primary Care Health Sciences, University of Oxford, Oxford, UK; and the Faculty of Medicine and Dentistry, University of Alberta, Edmonton, Alta. (Gill)

\section{References}

1. Fletcher J. What's next for CMAJ? CMAJ 2012; 184:507.

2. Gill P. Re: Effect of using reporting guidelines during peer review on quality of final manuscripts submitted to a biomedical journal: masked randomized trial [recent rapid response]. Available: www.bmj.com /content/343/bmj.d6783?tab=responses (accessed 2011 Mar. 25).

3. HINARI. List of HINARI journals. Geneva (Switzerland): The World Health Organization; 2012. Available: http://extranet.who.int/hinari /en/journalList_print.php (accessed 2011 Mar. 25).

4. Liew SM. Re: Effect of using reporting guidelines during peer review on quality of final manuscripts submitted to a biomedical journal: masked randomized trial. [recent rapid response to comment by Peter Gill]. Available: www.bmj.com/content/343 /bmj.d6783?tab=responses (accessed 2011 Mar. 25).

CMAJ 2012. DOI:10.1503/cmaj.112-2056

\section{Children with enuresis} ful overview of the diagnostic and therapeutic considerations involved in managing enuresis in children.$^{1}$ However, the importance of the abdominal examination, in particular the palpation for
Many thanks to Dr. Kiddoo for a help- stool, was somewhat glossed over. The potential for a stool-laden rectum to cause or worsen enuresis in children has been recognized for many years. ${ }^{2}$ In a recent retrospective study, Hodges and Anthony ${ }^{3}$ found that a significant fecal load, even without a history of constipation, may contribute to the pathophysiology of enuresis, and that laxative treatment with polyethylene glycol can help in resolving nighttime bedwetting. They suggest that an abdominal radiograph is not an unreasonable investigation to consider in addition to urinalysis and culture. Clinicians may wish to keep this in mind when faced with children who present with nocturnal enuresis.

\section{Edward S. Weiss}

Resident, Family Medicine, McMaster University, Hamilton, Ont.

\section{References}

1. Kiddoo DA. Nocturnal enuresis. CMAJ 2012;184: 908-11.

2. O'Regan S, Yazbeck S, Hamberger B, et al. Constipation a commonly unrecognized cause of enuresis. Am J Dis Child 1986;140:260-1.

3. Hodges SJ, Anthony EY. Occult megarectum-a commonly unrecognized cause of enuresis. Urology 2012;79:421-4.

\section{CMAJ 2012. DOI:10.1503/cmaj.112-2059}

Some letters have been abbreviated for print. See www.cmaj.ca for full versions and competing interests.

\section{- CORRECTION}

\section{Incorrect reference}

A Practice article in the Mar. 20 issue of CMAJ titled " 'Safety' technology: a hidden cause of diabetic ketoacidosis," contained an incorrect reference. Reference 11 should read as follows:

11. Bahl V, Antinori-Lent K. Transitioning from patient-specific insulin vials to patient-specific insulin pens a the bedside: Quality improvement or not? [meeting abstract]. American Diabetes Association 69th Scientific Sessions. 2009 June 5-9; New Orleans.

We apologize for the inconvenience this may have caused.

\section{Reference}

1. Yu CH. "Safety" technology: a hidden cause of diabetic ketoacidosis. CMAJ 2012;184:557-8.

CMAJ 2012. DOI:10.1503/cmaj.112-2058 